ISSN 2236-0859

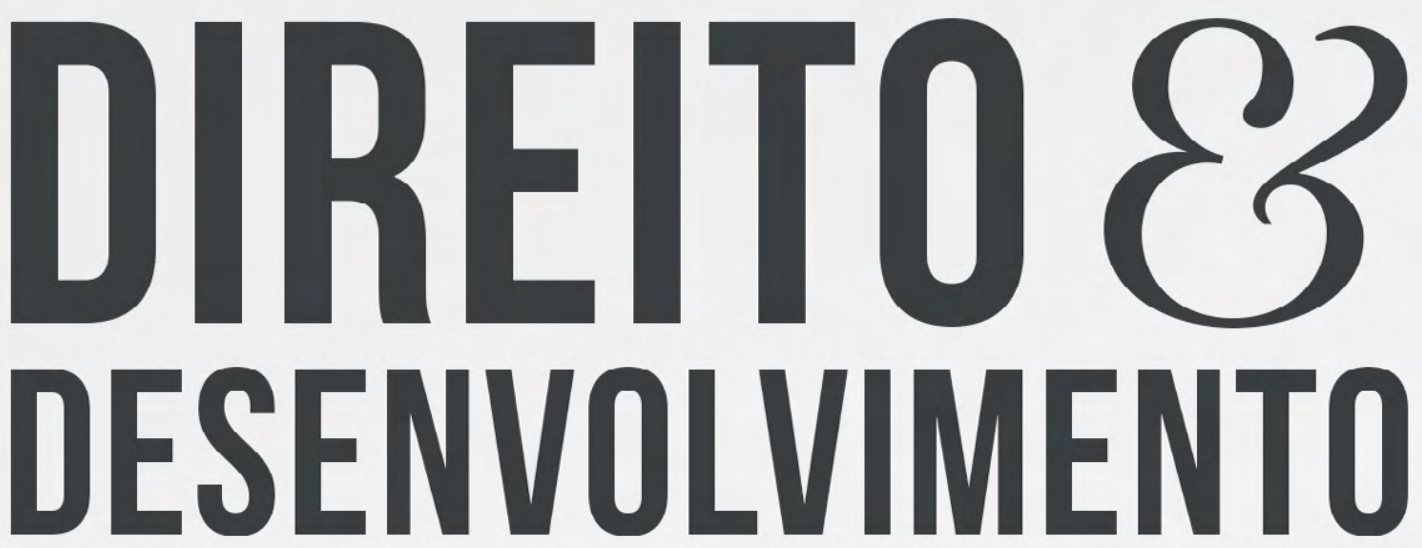

REVISTA DO PROGRAMA DE PÓS-GRADUAÇÃO EM DIREITO MESTRADO EM DIREITO E DESENVOLVIMENTO SUSTENTÁVEL

RECUPERAÇÃO JUDICIAL DE COOPERATIVAS: INTERPRETAÇÃO DA LEI 11.101/05 CONFORME A CONSTITUIÇÃOFEDERAL

JOSÉ BARROS CORREIA JÚNIOR VAGNER PAES CAVALCANTIFILHO 


\title{
RECUPERAÇÃO JUDICIAL DE COOPERATIVAS: INTERPRETAÇÃO DA LEI 11.101/05 CONFORME A CONSTITUIÇÃO FEDERAL
}

\author{
JUDICIAL RECOVERY'S COOPERATIVES: INTERPRETATION \\ OF LAW 11.101 / 05 ACCORDING OF THE FEDERAL CONSTITUTION
}

Recebido: $13 / 10 / 2017$

Aprovado: 25/03/2018

José Barros Correia Júnior* Vagner Paes Cavalcanti Filho**

\begin{abstract}
RESUMO: O presente estudo visa ampliar, mediante lastro constitucional, o alcance da Lei n. 11.101/o5, a denominada Lei de Falências e Recuperação judicial e extrajudicial, às sociedades cooperativas, haja vista os avanços decorrentes da própria lei e o panorama de grave crise econômica, uma vez que estas não se sujeitam ao regime falimentar e não aprofundam a adequação à recuperação judicial. Sob essa perspectiva, o trabalho visa promover uma nova visão sobre o conceito de empresa e sua função social, independente da sua natureza associativa sem finalidade lucrativa, partindo-se, para isso, do centro do ordenamento jurídico, qual seja a Constituição Federal de 1988, numa perspectiva de defesa ao interesse coletivo, em benefício ao cooperativismo e ao desenvolvimento social e econômico. A importância dessa produção reside em debater uma matéria que até então não tem sido aprofundada, muito pelo contrário, a ilegitimidade ativa das cooperativas em sede falimentar tem sido aceita com bastante parcimônia pela doutrina. Nesta senda, defende-se a finalidade precípua da preservação das atividades das cooperativas, fruto do princípio da função social da propriedade, do qual se extrai a função social da empresa e todo o complexo empreendimento que move a economia local, regional e até mesmo nacional, evitando, desta forma, o impacto nefasto da quebra da cadeia produtiva que pode decorrer da extinção de determinada sociedade, sendo irrelevante para o desiderato constitucional se tratar de sociedade civil ou empresária.
\end{abstract}

Palavras-chave: Cooperativas. Recuperação judicial. Constituição Federal.

\begin{abstract}
The aim of this study is to expand, through constitutional analysis, the scope of the Law n. 11.101 /05, the so-called Bankruptcy and Judicial and Extrajudicial Recovery Law, to cooperative societies, given the advances arising from the law itself and the panorama of an serious economic crisis, once they are not subject to the bankruptcy regime and do not deepen the adequacy of judicial recovery. From this perspective, the objective of this work is to promote a new vision about the concept of a company and its social function, independent of its associative nature without a lucrative purpose, starting from the center of the legal system, namely the Federal Constitution of 1988, from a perspective of defense of collective interest, to the benefit of cooperativism and social and economic development. The importance of this production lies in debating a matter that has not been studied until now, quite the contrary, the active illegitimacy of cooperatives in bankruptcy has been accepted parsimoniously in doctrine. In this way, the main purpose of the preservation of the activities of cooperatives is defended, as a result of the principle of the social function of the property, from which the social function of the company is extracted and the whole complex enterprise that activates the local, regional and even national economy, avoiding, in this way, the harmful impact of the breakdown of the productive chain that can result from the extinction of a certain society, being irrelevant to the constitutional desiderate whether it is a civil society or a business person.
\end{abstract}

Keywords: Cooperatives. Judicial recovery. Federal constitution.

\footnotetext{
* Doutor em Direito pela Universidade Federal de Pernambuco. Mestre em Direito Privado pela Universidade Federal de Pernambuco. Professor de Direito Empresarial da Universidade Federal de Alagoas. Maceió/AL. Brasil. E-mail: jbarroscjr@msn.com.

** Mestrando em Direito pela Universidade Federal de Alagoas. Especialista em Direito Civil e Empresarial pela Universidade Federal de Pernambuco. Maceió/AL. Brasil. E-mail: vagnerpaa@gmail.com
} 


\section{INTRODUÇÃO}

O instituto da recuperação judicial introduzido pela Lei №. 11.101/2005 possibilitou um grande avanço no campo direito empresarial, notadamente, ao permitir a preservação da sociedade empresária enquanto instrumento de produção, circulação de riqueza e geração de emprego, imprescindíveis para o desenvolvimento econômico e social do país.

Apesar dos avanços decorrentes da Lei de Recuperação Judicial para milhares de empresários brasileiros em momento de grave crise econômica, faz-se necessário debater a sua abrangência em relação às sociedades cooperativas, para as quais a jurisprudência pátria tem negado sua aplicação.

Nunca houve o devido aprofundamento da matéria, tendo sido aceita com parcimônia a tese de que as sociedades cooperativas não teriam legitimidade ativa para propor a recuperação por não serem espécie de sociedades empresárias à luz da legislação pátria, assim como, pelo fato de as cooperativas não estarem submetidas ao procedimento de falência judicial, mas sim à liquidação extrajudicial.

De fato, o Código Civil de 2002 introduziu significativas mudanças na legislação, suplantando a antiga teoria dos atos de comércio e incorporando a teoria da empresa em nosso ordenamento jurídico (RAMOS, 2012, p. 15), onde a figura central é o empresário, aquele que "exerce profissionalmente atividade econômica organizada para a produção ou a circulação de bens e serviços" (art. 966 do Código Civil).

No entanto, manteve a distinção entre sociedades civis e empresariais, as quais estariam divididas justamente pelo regime jurídico empresarial a que estão submetidas estas últimas, o que levou a muitas críticas por parte da doutrina, como se extrai das ponderações de Koury (2005, p. 3-5):

Isto ocorreu porque o legislador ficou "no meio do caminho", não tendo logrado sequer unificar as obrigações civis e comerciais e com a extensão da falência aos nãocomerciantes. [...] No que diz respeito à sociedade simples, Reale esclareceu, na mesma obra, que é aquela que tem por escopo a realização de operações econômicas de natureza não-empresarial, em distinção que retoma o critério casuístico dos atos de comércio.

Com os avanços tecnológicos e as significativas mudanças no cenário social, onde as pessoas passam a buscar cada dia novas formas de interação visando agregar esforços para a produção de bens e serviços, dando origem a uma infinidade de relações jurídicas novas, essa dicotomia estanque não mais responde às necessidades oriundas desses recentes fenômenos de forma adequada e compatível com a realidade subjacente.

Por conseguinte, torna-se imperiosa uma investigação mais acurada sobre o alcance das normas que delimitam o âmbito das sociedades empresariais e das normas insertas na Lei de Recuperação Judicial para cotejá-las com as diretrizes constitucionais necessárias à coesão e aplicação sistêmica do ordenamento jurídico, na esteira do processo de constitucionalização dos direitos, cuja consequência direta é precisamente a releitura dos institutos civis e comerciais à luz da Constituição, como bem assinala José Afonso da Silva:

Nessa perspectiva e pautando-se na Constituição Federal como vértice máximo e conformador de toda e qualquer criação, interpretação e aplicação da legislação civil e comercial, faz-se necessário o entendimento de que cabe ao operador do Direito interpretar o Código Comercial segundo a Constituição e não a Constituição segundo o Código, conforme ocorre de forma corriqueira. (SILVA, 2015, p. 1)

Daí a relevância do presente estudo: alargar os horizontes para permitir uma nova visão sobre o conceito de empresa e sua função social, notadamente, das sociedades cooperativas, independente da sua natureza associativa sem finalidade lucrativa, partindo-se do centro do ordenamento jurídico, qual seja a Constituição Federal de 1988, harmonizando a partir desta todas as demais emanações legislativas para ao final buscar a interpretação mais consentânea com a nova ordem vigente. 


\section{A FUNÇÃO SOCIAL DA EMPRESA COMO ELEMENTO CERNE DA RECUPERAÇÃO JUDICIAL}

Toda a estruturação do instituto da recuperação judicial foi desenhada em torno da ideia da preservação da empresa, aplicando o preceito constitucional da função social da propriedade ao direito empresarial, compreendendo ser a empresa elemento indispensável ao desenvolvimento social do país.

O princípio da função social surge num contexto de objeção à noção eminentemente individualista inerente ao direito de propriedade ao longo da história, tendo por inspiração mais próxima a Doutrina Social da Igreja, exposta nas Encíclicas Mater et Magistra, do Papa João XXIII, de 1961, e Centesimus cennus, de 1991, de João Paulo II, quando se passa a ser concebida como um instrumento para a criação de bens necessários à subsistência humana (DI PIETRO, 2013, p. 135).

Entretanto, no plano jurídico, atribui-sea Leon Duguit, já no iníciodo séculoXX, odesenvolvimento da ideia central de que a propriedade não seria mais um direito subjetivo do proprietário, mas sim a função social do detentor de riqueza (ROCHA, 2005, p. 7o).

O princípio da função social da empresa, por conseguinte, é corolário do princípio da função social da propriedade, da qual a empresa é a sua feição dinâmica, "composta pela conjugação de bens corpóreos e incorpóreos, organizados profissionalmente para produzir riquezas, daí porque é uma 'fonte de poder', uma função" (GRAU, 2007, p. 241-242).

Para a doutrina mais moderna, a função social da empresa seria contemplada e teria utilidade social quando propiciasse melhor locação de recursos e geração de riquezas. Assim, sua utilidade social decorreria da sua eficiência e estaria expressa no resultado da sua atividade tendo em vista os postos de trabalho gerados, os tributos e sua contribuição para o bem estar coletivo (FRANCO, 2015, p. 231).

Neste sentido, estabelece o art. 47 da Lei № 11.101/05, cujos termos reputamos de fundamental importância transcrever:

Art. 47. A recuperação judicial tem por objetivo viabilizar a superação da situação de crise econômico-financeira do devedor, a fim de permitir a manutenção da fonte produtora, do emprego dos trabalhadores e dos interesses dos credores, promovendo, assim, a preservação da empresa, sua função social e o estímulo à atividade econômica.

Da simples leitura do dispositivo acima citado, percebe-se a imprescindibilidade de a recuperação judicial visar não apenas o soerguimento da empresa combalida, mas também os interesses dos credores, função social da atividade produtiva e estímulo à atividade econômica.

Uma variada gama de interesses está presente em uma recuperação judicial, vez que a manutenção da empresa considerada viável representa a manutenção de empregos (renda familiar), tributos (previdência social, serviços públicos e manutenção da máquina estatal), estímulo à atividade econômica e satisfação dos credores (colaboradores empresariais). Leia-se a respeito, posição abalizada de Sérgio Campinho (2015, p. 128):

O instituto da recuperação vem desenhado justamente com o objetivo de promover a viabilização da superação desse estado de crise, motivado por um interesse na preservação da empresa desenvolvida pelo devedor. Enfatize-se a figura da empresa sob a ótica de uma unidade econômica que interessa manter, como um centro de equilíbrio econômico-social. É, reconhecidamente, fonte produtora de bens, serviços, empregos e tributos que garantem o desenvolvimento econômico e social de um país. A sua manutenção consiste em conservar o "ativo social" por ela gerado. A empresa não interessa apenas ao seu titular - o empresário -, mas a diversos outros atores do palco econômico, como os trabalhadores, investidores, fornecedores, instituições de crédito, ao Estado, e, em suma, aos agentes econômicos em geral. Por isso é que a solução para a crise da empresa passa por um estágio de equilíbrio dos interesses públicos, coletivos e privados que nela convivem. 
Logo, o escopo da lei não consiste unicamente em preservar o empresário (pessoa jurídica) em situação de crise econômico-financeira, mas, sobretudo, permitir a "manutenção da fonte produtora, do emprego dos trabalhadores e dos interesses dos credores, promovendo, assim, a preservação da empresa, sua função social e o estímulo à atividade econômica" (MAMEDE, 2012, 119). Em outras palavras, visa preservar a atividade, propriedade dinâmica:

Logo, quando se analisa a função social da empresa, há de se delinear os conceitos que envolvem o instituto, já que a função social pode se dar em relação à propriedade exercida pelo empresário no tocante aos bens que compõem o estabelecimento empresarial, ou, por outro lado, pode-se analisar a função social da empresa propriamente dita, enquanto atividade organizada pelo empresário, que visa otimizar a produção para o mercado (CHALHUB, 2003, p. 3).

Vislumbra-se, desta maneira, que o intuito primacial do instituto da recuperação judicial é a preservação de tudo aquilo que a atividade econômica representa para a sociedade e não a figura do empresário propriamente dito, não sendo razoável qualquer restrição ao uso de tal prerrogativa legal em razão de uma classificação infralegal, tomando-se os meios pelos fins e olvidando a própria essência do instituto. A propósito, leia-se:

Tive oportunidade de propor, neste sentido, o reconhecimento da personalidade jurídica das empresas que desempenham função social, com marcante poder no mercado e grande importância individual, na medida em que não envolvem apenas os interesses dos trabalhadores, administradores e prestadores de capital, como também os interesses da comunidade em geral e do poder público. Essas empresas poderiam ser constituídas consoante qualquer uma das formas societárias disponibilizadas pelo ordenamento jurídico. Esclareci então: "É evidente que essas empresas, que têm função social, não podem ser reduzidas ao âmbito societário, confinadas aos estreitos limites do Direito privado e da soberania individual, confundindo-se o controle empresarial com a propriedade nos moldes clássicos." (KOURY, 2010, p. 7).

Sendo assim, chega-se a primeira premissa sobre a qual se deita nosso objeto de estudo, qual seja: o princípio da função social da empresa como elemento nuclear do instituto da recuperação judicial, desmistificando as vetustas noções de cunho estritamente liberal focadas na proteção individual do empresário, incompatíveis com o processo de repersonalização do direito civil e empresarial, por meio do qual passou a se "revalorizar a pessoa humana como verdadeiro fim do Direito" (CORREIA JUNIOR, 2012, p. 1).

\section{DOS ÓBICES À UTILIZAÇÃO DA RECUPERAÇÃO JUDICIAL PELAS COOPERATIVAS}

Percebe-se que todas as interpretações, ou a maior parte delas, vêm sendo elaboradas sem qualquer preocupação com o arcabouço jurídico constitucional, tampouco tem sido questionado qual o fundamento de ordem axiológica capaz de afastar do âmbito de incidência da Lei no. 11.101/2005 as cooperativas, quando a Constituição Federal estimula a sua formação por parte dos indivíduos.

Isto se deve principalmente ao fato de não ser empreendido maior esforço interpretativo, restringindo-se boa parte da doutrina ao método de subsunção da hipótese normativa à espécie fática, razão pela qual se torna conveniente analisar de forma minuciosa e sistemática os dispositivos normativos que regem a matéria em evidência.

A princípio, merece destaque o fato de que a Lei ㄲo. 11.101/2005 é aplicável tanto aos empresários quanto às sociedades empresárias, a teor do que preconiza o seu art. $1^{\circ}$, em evidência: Art. $1^{\circ}$ Esta Lei disciplina a recuperação judicial, a recuperação extrajudicial e a falência do empresário e da sociedade 
empresária, doravante referidos simplesmente como devedor. (BRASIL; 2005).

Por sua vez, o Código Civil ao revogar parcialmente o vetusto Código Comercial, cuidou de definir o conceito de empresário, leia-se: "Art. 966. Considera-se empresário quem exerce profissionalmente atividade econômica organizada para a produção ou a circulação de bens ou de serviços" (BRASIL; 2002).

De tal sorte, desde a entrada em vigor do Código Civil de 2002, a sujeição às normas de Direito Empresarial passaram a depender do conceito de empresário segundo a teoria da empresa (COELHO, 2015, 42), delimitando, por decorrência lógica, o âmbito de incidência da lei de recuperação judicial objeto de nossos estudos.

Nesta senda, dois seriam os óbices considerados como intransponíveis à aplicação do procedimento de recuperação judicial às sociedades cooperativas, quais sejam: o primeiro cinge-se ao fato de serem consideradas sociedades simples à luz do art. 982 do CC/o2; o segundo está relacionado com a sua submissão ao procedimento de liquidação extrajudicial.

No que concerne à classificação das sociedades cooperativas como sociedades simples, trata-se de um dos pontos mais criticados do Código Civil, posto ter mantido a velha dicotomia entre sociedades civis e mercantis, alterando apenas a nomenclatura adotada e insistindo numa distinção que pouco contribui para o aperfeiçoamento da disciplina.

Essa dicotomia preservada em nosso ordenamento é anacrônica, remonta a velha separação entre direito civil e comercial de outrora, carece de lógica e não se mostra consentânea com o princípio da função social da empresa. Convém o magistério de Rubens Requião (2008, p. 23-24):

\begin{abstract}
Em nossa opinião será ilusória a unificação do direito obrigacional se permanecer a falência como instituto especificamente mercantil. Não será possível atingir a verdadeira unificação enquanto persistir a divisão básica no trato do empresário civil e do empresário comercial, da sociedade civil e da sociedade comercial, no que diz respeito à insolvência. [...] Se, portanto, se pretende unificar o direito privado em nosso país, que se proceda racionalmente, com lógica e determinação. Comece-se pela codificação uma e, concomitantemente, estenda-se a falência aos não-comerciantes. Assim, ao deparar-se com a insolvência, não haveria necessidade de indagar-se se o empresário é comerciante ou civil. Desapareceria a necessidade de classificação do empresário entre comerciante civil bem como no que respeita às sociedades.
\end{abstract}

De outro norte, parte significativa da doutrina nacional afirma que as cooperativas, como espécies de sociedades simples, não estão abrangidas pela Lei n. 11.101/2005, o primeiro chegando a afirmar que as sociedades cooperativas estão fora do campo de abrangência por não possuírem objetivos lucrativos (FAZZIO JÚNIOR. 2008).

Realmente, a Lei o․ 5.764/71 em seu art. $3^{\circ}$, considera como sociedades cooperativas "as pessoas que reciprocamente se obrigam a contribuir com bens ou serviços para o exercício de uma atividade econômica, de proveito comum, sem objetivo de lucro" (BRASIL; 1971).

Contudo, muito embora não tenham de fato a possibilidade de auferir o lucro de sua atividade, não é menos verdade o fato de que são as sociedades cooperativas entidades que atuam como agentes econômicos responsáveis pela produção e circulação de bens e serviços, possuindo, assim, grande repercussão no desenvolvimento social e econômico no meio em que atuam.

É preciso, pois, compreender que o objeto de preservação jurídica é antes de tudo o aspecto social da propriedade dinâmica e o valor social do trabalho, consoante delineado alhures, e não o empresário propriamente dito. Este também deve ser preservado, mas não por representar um fim em si mesmo, mas justamente por ser uma fonte de geração de emprego e renda, assim como permitir a circulação de bens e propiciar distribuição de renda, aspectos de insofismável tez social.

Logo, não se vislumbra qualquer intento ou razão jurídica para se pretender afastar do rol dos legitimados ao pleito de recuperação judicial as sociedades cooperativas, pois também são agentes de produção econômica e de geração de emprego. 
Ademais, a delimitação da condição de empresa é dada à luz do nosso sistema jurídico vigente, o qual não pode mais exigir o escopo lucrativo como requisito para se enquadrar determinada sociedade como empresarial, sobretudo diante das relevantes transformações ocorridas na estrutura socioeconômica.

\begin{abstract}
Mas, por outro lado, identificar o empresário como mero sucessor do comerciante é asserção que se revela impregnada de um apego histórico injustificado que acaba por escamotear as profundas transformações ocorridas na estrutura socioeconômica e, por via de consequência, jurídica, do que decorre manifesto prejuízo para a compreensão do atual significado do direito da empresa. Com efeito, o direito comercial, guiado pelo avanço capitalista, criou novas realidades não explicadas juridicamente pelas categorias tradicionais do direito, pondo em destaque, assim, as transformações socioeconômicas, que foram apreendidas por diversos ramos do direito que, ao se desenvolverem, acabaram por colocar em xeque a própria existência do direito comercial. (CAVALLI, 2010, p. 1)
\end{abstract}

Atualmente, tem se recorrido ao que se convencionou denominar de "transeficácia teórica da empresa" (CORREIA JUNIOR, 2013, p. 24), para permitir justamente um alargamento do conceito de empresa à luz das ciências econômicas e da teoria da análise econômica do direito, dando novos ares a um instituo em constante mutação. Nesse sentido, calha a seguinte passagem sobre o tema:

Portanto, a empresa como função poderia ter seu conceito econômico-jurídico dissecado nos seguintes itens: a) atividade, como intenção de conjuntos de atos, não eventuais, realizados ou não, mas valendo a vontade de exercê-los desta forma; b) econômica, com objetivo eventual de circulação de riquezas e aquisição de lucros; lucro como meio, por não ser o objetivo da empresa, mas do empresário, que nem sempre o efetiva, pois o objetivo de lucro é elemento da empresa, mas o lucro em si, não; c) organizada, como fator de agregação de todos os elementos da empresa; e d) com finalidade de produção e/ou circulação de bens e/ou serviços, como adoção da teoria da empresa e afastamento dos atos de comércio, não se distinguindo mais em atos civis e comerciais, teoria que resultou em mais problemas do que soluções após a massificação das relações econômicas (CORREIA JUNIOR, 2013, p. 31).

O Conselho da Justiça Federal, inclusive, reconheceu a insuficiência dos critérios legais para apartar de forma estanque os atos praticados pelas sociedades cooperativas dos atos praticados pelas sociedades empresárias, como se faz claro do Enunciado no. 207: "Art. 982: A natureza de sociedade simples da cooperativa, por força legal, não a impede de ser sócia de qualquer tipo societário, tampouco de praticar ato de empresa". (BRASIL, 2007).

Não de pode olvidar, ainda, o fato de o direito comercial ser fruto da prática e da constância das atividades econômicas desenvolvidas ao longo do tempo, razão pela qual a dicotomia mantida no Código Civil é contrária à própria flexibilidade histórica inerente a este ramo do direito em constante mutação.

Por sua vez, a atual Lei de Falências e Recuperação Judicial não exclui do procedimento de recuperação, as cooperativas, fazendo alusão expressa somente às cooperativas de crédito, vejamos:

\footnotetext{
Art. $2^{\circ}$ Esta Lei não se aplica a:

I - empresa pública e sociedade de economia mista;

II - instituição financeira pública ou privada, cooperativa de crédito, consórcio, entidade de previdência complementar, sociedade operadora de plano de assistência à saúde, sociedade seguradora, sociedade de capitalização e outras entidades legalmente equiparadas às anteriores. (BRASIL; 2005)
}

Em relação às sociedades cooperativas, a Lei no. 5·764/71, responsável pelo seu delineamento jurídico, excluiu a participação das cooperativas tão somente do processo falimentar ao dispor em seu art. $4^{\circ}$, a saber: 


\begin{abstract}
Art. $3^{\circ}$ Celebram contrato de sociedade cooperativa as pessoas que reciprocamente se obrigam a contribuir com bens ou serviços para o exercício de uma atividade econômica, de proveito comum, sem objetivo de lucro.

Art. $4^{\mathbf{0}}$ As cooperativas são sociedades de pessoas, com forma e natureza jurídica próprias, de natureza civil, não sujeitas a falência, constituídas para prestar serviços aos associados, distinguindo-se das demais sociedades pelas seguintes características. (BRASIL; 1971)
\end{abstract}

Ainda segundo a lei de regência, tais sociedades deverão submeter-se a um procedimento de liquidação próprio, por meio do qual serão geridos os passivos e ativos de forma a permitir, ao máximo, o adimplemento dos credores.

Por conseguinte, passou a ser aceita a tese de que às sociedades cooperativas não assistiria ao tratamento dispensado pela Lei no $11.101 / 2005$, no que tange ao procedimento de recuperação judicial.

Tal entendimento passou a reinar de forma mansa em nossas cortes, como se pode observar da decisão prolatada pelo Tribunal de Justiça de Minas Gerais, reformando uma decisão em que o magistrado aplicava a Lei no. 11.101/2005 às sociedades cooperadas:

Agravo de instrumento. Ação de recuperação judicial. Art. 1º, da Lei ํo 11.101, de 2005 . Cooperativa. Sociedade simples. Recuperação judicial de empresa inviável. Recurso

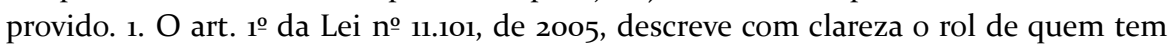
direito à recuperação judicial de empresa, quais sejam, o empresário e a sociedade empresária. 2. A cooperativa é sociedade simples de pessoas, nos termos do parágrafo único do art. 982 do Código Civil de 2002. Logo, não tem direito à recuperação judicial, circunstância que torna o pedido juridicamente impossível. 3. Agravo de instrumento conhecido e provido para indeferir o pedido da recuperação judicial da agravada, preliminar rejeitada. (TJMG - Agravo de Instrumento-Cv 1.0019.11.00o925-5/003, Relator(a): Des.(a) Caetano Levi Lopes , 2ª CÂMARA CÍVEL, julgamento em 22/11/2011, publicação da súmula em 20/01/2012)

No mesmo sentido é a decisão proferida pelo Tribunal de Justiça do Rio Grande do Sul, em vértice:

AGRAVO DE INSTRUMENTO. PEDIDO DE RECUPERAÇÃO JUDICIAL. COOPERATIVA AGROINDUSTRIAL. PRODUTOS E SERVIÇOS. VEDAČ̃O LEGAL. INAPLICABILIDADE DA LEI 11.101/05 ÀS COOPERATIVAS. IMPOSSIBILIDADE JURÍDICA DO PEDIDO. EXTINÇÃO DO FEITO. ARTIGO 267, VI, DO CPC. RECURSO PROVIDO. A Lei 11.101/o5, ao regular o procedimento de Recuperação Judicial de empresas, exclui, expressamente, a sua aplicação às cooperativas de crédito e outras legalmente equiparadas. Pedido juridicamente impossível, ensejando a extinção do feito, com amparo no artigo 267, VI, do caderno processual. Proveram o agravo de instrumento. Unânime. (Agravo de Instrumento № 70039202056, Sexta Câmara Cível, Tribunal de Justiça do RS, Relator: Artur Arnildo Ludwig, Julgado em 27/o1/2011)

Entretanto, é preciso reconhecer que o antigo procedimento de liquidação extrajudicial é obsoleto, bem como tem se mostrado excessivamente demorado, custoso e ineficiente, dada a carência de pessoal especializado, administradores profissionais, além de ocorrer fora do judiciário, sofrendo, em algumas situações desvirtuamentos por força da interferência política indevida (SCALZILLI, 2014, 3).

Frise-se, ainda, que a previsão da liquidação extrajudicial foi prevista pela Lei no. 5.764/71, ou seja, na década de 7o, quase vinte anos antes da Constituição Federal e quase 35 anos antes do advento da Lei de Recuperação Judicial, trazendo um procedimento que se realiza exclusivamente no âmbito da empresa, deixando os credores a mercê dos responsáveis nomeados pelos associados em Assembleia Geral e podendo por ela ser destituídos, nos termos da lei de regência: 
Art. 65. Quando a dissolução for deliberada pela Assembléia Geral, esta nomeará um liquidante ou mais, e um Conselho Fiscal de 3 (três) membros para proceder à sua liquidação.

Art. 67. Os liquidantes terão todos os poderes normais de administração podendo praticar atos e operações necessários à realização do ativo e pagamento do passivo. (BRASIL; 1971)

Diferentemente, o modelo de recuperação extrajudicial instituído pela Lei no..11.101/2005apresentase muito mais consentâneo e eficaz para o processo de soerguimento econômico das sociedades, pois além de criar melhores condições para a atuação da lógica do mercado na superação de crises nas empresas devedoras (COELHO, 2015, p. 526), propicia maior segurança jurídica ao possibilitar a sua homologação judicial.

Contudo, o ponto fulcral diz respeito à inexistência de previsão legal de qualquer mecanismo de soerguimento das sociedades cooperativas, razão pela qual se torna imprescindível aprofundar o tema e abrir algumas cortinas para deixar adentrar ao campo do direito empresarial normas de índole constitucional e assegurar um alcance maior do que a letra fria da lei nos permite enxergar.

\section{DA INTERPRETAÇÃO CONFORME A CONSTITUIÇÃO DA LEI 11.101/05}

Fincados estes lastros, constata-se que a fonte primária sob qual veio a se debruçar a novel legislação empresarial é o princípio da função social da empresa, cujo status constitucional é decorrência da conjugação do fundamento da livre iniciativa e do princípio da função social da propriedade insculpidos no artigo 170 da Constituição Federal de 1988, em destaque:

Art. 170. A ordem econômica, fundada na valorização do trabalho humano e na livre iniciativa, tem por fim assegurar a todos existência digna, conforme os ditames da justiça social, observados os seguintes princípios:

II - propriedade privada;

III - função social da propriedade; (BRASIL, 1988)

Diante de um momento de grave crise econômica pela qual passa a sociedade, torna-se imprescindível o reconhecimento de novos instrumentos aptos a promover e assegurar a preservação da atividade econômica e o desenvolvimento social do país, privilegiando, por exemplo, a inclusão de sociedades cooperativas no procedimento de recuperação judicial.

Nesse sentido, torna-se imprescindível a adoção de uma interpretação sistemática e que permita atender ao princípio da unidade da Constituição, assegurando-se o sentido da norma que melhor permita a harmonização dos valores albergados na Lei Maior (BARROSO, 2013, p. 326).

Fala-se isto, porque em diversas passagens é possível se extrair do texto constitucional o dever de incentivo ao cooperativismo, reflexo da sua relevância para no contexto social do país:

Art. 174. Como agente normativo e regulador da atividade econômica, o Estado exercerá, na forma da lei, as funções de fiscalização, incentivo e planejamento, sendo este determinante para o setor público e indicativo para o setor privado. [...]

$\S 2^{\text {o }}$ - A lei apoiará e estimulará o cooperativismo e outras formas de associativismo.

Art. 187. A política agrícola será planejada e executada na forma da lei, com a participação efetiva do setor de produção, envolvendo produtores e trabalhadores rurais, bem como dos setores de comercialização, de armazenamento e de transportes, levando em conta, especialmente: [...]

VI - o cooperativismo; (BRASIL; 1988) 
Decerto, também, que se é desejo do Estado, a formação e desenvolvimento de atividades por meio do cooperativismo para o desenvolvimento econômico e social, também deve ser a sua manutenção, diante de tudo o que representa e dos reflexos sociais que adviriam em caso de sua extinção.

Calha a advertência de Carlos Maximiliano (1993, p. 183) em sua célebre frase tantas vezes citadas, "deve o direito ser interpretado inteligentemente, não de modo a que a ordem legal envolva um absurdo, prescreva inconveniências, vá ter conclusões inconsistentes ou impossíveis".

Assim, como poderia o ordenamento jurídico, diga-se de passagem, por expressa dicção constitucional incentivar o cooperativismo, fomentar a produção agrícola de forma associativa e ao mesmo tempo negar acesso a um meio lídimo de manutenção de sua atividade produtiva?

Seria um contrassenso teratológico, dada a devida vênia, aceitar que um instituto, cuja razão de ser encontra-se plasmada na função social da propriedade para beneficiar empresas lucrativas, poderia deixar de ser aplicado justamente a empresas cuja existência é a própria função social que desempenham ao exercerem atividade produtiva, contribuindo para o crescimento do país, geração de emprego e renda.

De tal feita, mostra-se incoerente a aplicação do método tradicional de subsunção do fato à norma, superado há muito pelo pós-positivismo, impondo ao intérprete, em especial, ao juiz, a utilização de novos elementos de interpretação (BARROSO, 2013, p. 313), dentre os quais se destacam a interpretação sistemática, por meio da qual se extrai a unidade e harmonia do ordenamento jurídico, e a teleológica, donde se pressupõe que o direito tem por escopo atender a determinados fins do Estado. Conveniente, aliás, é o recorrente apontamento de Eros Grau (2002, p. 34):

Não se interpreta o direito em tiras, aos pedaços. A interpretação de qualquer texto de direito impõe ao intérprete, sempre, em qualquer circunstância, o caminhar pelo percurso que se projeta a partir dele - do texto- até a Constituição. Um texto de direito isolado, destacado, desprendido do sistema jurídico, não expressa significado algum.

Qualquer outra interpretação estaria inquinada de grave visgo de inconstitucionalidade, pois incompatível com a Constituição Federal, em especial, com o art. $5^{\circ}$, XXIII, 170, III, 174, §2º e e 187 VI, na medida em que pretende dar tratamento prejudicial a determinada categoria que, por expressa dicção constitucional, deveria ser beneficiada.

Seria conceber o fechamento das cooperativas em detrimento da sua manutenção com lastro na função social da propriedade e da empresa, em claro e inequívoco descompasso com a Carta de 1988.

Por isso mesmo, a única interpretação jurídica possível é justamente aquela que procura se colmatar à Norma Fundamental, sob o risco de admitirmos leis incompatíveis com a sua própria fonte de validade.

Cuida-se, a toda evidência, de método hermenêutico introduzido pelo pós-positivismos denominado de "interpretação conforme a Constituição", sobre o qual discorreu conspicuamente o constitucionalista Paulo Bonavides (2006, p. 518):

Uma norma pode admitir várias interpretações. Destas, algumas conduzem ao reconhecimento de inconstitucionalidade, outras, porém, consentem tomá-la por compatível com a Constituição. O intérprete, adotando o método ora proposto, há de inclinar-se por esta última saída ou via de solução. A norma, interpretada "conforme a Constituição", será portanto considerada constitucional. Evita-se por esse caminho a anulação de lei em razão de normas dúbias nela contidas, desde naturalmente que haja a possibilidade de compatibilizá-las com a Constituição. A aplicação desse método parte, por conseguinte, da presunção de que toda lei é constitucional, adotando-se ao mesmo passo o princípio de que em caso de dúvida a lei será interpretada "conforme a Constituição". Deriva outrossim do emprego de tal método a consideração de que não se deve interpretar isoladamente uma norma constitucional, uma vez que do Conteúdo geral da Constituição procedem princípios elementares da ordem constitucional, bem como decisões fundamentais do constituinte, que não podem ficar ignorados, 
cumprindo levá-los na devida conta por ensejo da operação interpretativa, de modo a fazer a regra que se vai interpretar adequada a esses princípios ou decisões. Daqui resulta que o intérprete não perderá de vista o fato de que a Constituição representa um todo ou uma unidade e, mais do que isso, um sistema de valor.

Para mais além, seria admitir uma aplicação da lei em dissonância com a realidade social, a qual deve ser levada em consideração no momento da aplicação da norma, já que "não há interpretação sem relação social" (STRECK, 2003, p. 19).

Dentre os argumentos que legitimam uma ampliação da interpretação atribuída à lei de recuperação judicial, merece relevo o econômico, uma vez que somente o setor agropecuário conta com mais de 1.600 sociedades cooperativas e são responsáveis por $2,5 \%$ do PIB nacional ${ }^{3}$, assim como o fato de o atual procedimento de liquidação extrajudicial não possuem a mesma efetividade da recuperação judicial, como destacado por Scalzilli (2014, p. 3):

As liquidações extrajudiciais previstas em leis específicas e aplicadas de forma setorial como no caso das cooperativas, instituições financeiras e seguradoras têm se mostrado excessivamente demoradas, custosas e sem atingir o seu principal objetivo, que é a venda dos ativos e o pagamento dos credores. Falta aparelhamento, pessoal especializado, administradores profissionais, fora que, em alguns casos, os efeitos políticos desvirtuam ou aumentam tais obstáculos.

Não assiste razão, pois, o afastamento do princípio da preservação da empresa das sociedades cooperativas, uma vez se tratarem de sociedades dispostas à produção de bens e serviços, produzindo riquezas e gerando emprego e receitas aos cofres públicos, de modo que não permitir sua subsistência seria fazer vista grossa ao princípio da função social da propriedade. Uma das poucas vozes a soprar contra o vento vem de Tokars (2009):

A este argumento hermenêutico soma-se outro, ainda mais relevante: a viabilidade da recuperação de cooperativas é uma medida de cumprimento da função social do direito. Afinal, se não se autoriza a recuperação em favor de uma cooperativa em situação de crise financeira sanável, a alternativa seria a sua liquidação. Alternativa que, como é evidente, a todos prejudica. Assim como se prevê para as empresas em geral, as cooperativas deveriam ser preservadas em caso de crise financeira sanável. Esta medida protegeria os interesses dos cooperados e de seus credores, já que a manutenção da atividade econômica gera renda a uns e possibilidade de recebimento a outros. De nada adianta pensar em economia solidária ou em incentivo ao cooperativismo se, no momento da crise, as cooperativas estão menos protegidas do que os empresários em geral. Soluções devem ser buscadas, em especial nesta época de crise, seja por meio de uma lei que elimine dúvidas, seja por meio de uma interpretação focada na função social da lei atual.

Some-se a isto tudo, o fato de que o processo de liquidação foi previsto na década de 7o, tornando-se defensável a sua incompatibilidade para as sociedades cooperativas que não atuem no sistema financeiro de crédito, estas afastadas expressamente da Lei de Recuperação Judicial, aplicando-se as demais todos os meios lídimos a preservação das sociedades e tudo aquilo que representam em termos econômicos e sociais.

Para mais além, por se constituir o procedimento de recuperação judicial em verdadeira operacionalização da função social da empresa, poder-se-ia levantar os mesmos argumentos outrora aventados para defender a tese pela sua incompatibilidade superveniente com a ordem jurídica posta. Mas isso seria assunto para outra ocasião.

Sendo assim, propõe-se uma ponderação hermenêutica para atribuir às normas insertas na Lei oㅡ. 11.101/2005 sentido que melhor realize os mandamentos constitucionais, ampliando seu espectro de incidência e albergando as sociedades cooperativas, tornando-a congruente com o princípio da função social da empresa.

3 <http://www.valor.com.br/legislacao/359410o/cooperativas-e-recuperacao-judicial>. Acesso em 27.01.2017 


\section{CONSIDERAÇÕES FINAIS}

A partir daquilo que se convencionou denominar como constitucionalização do Direito, por meio do qual houve a devida revalorização da norma fundamental durante muito tempo relegada a um papel meramente programático, do modo que toda e qualquer análise jurídica não mais pode ser considerada adequada se não partir da Constituição Federal de 1988.

Isto porque a Constituição é a norma que serve de alicerce de validade de toda ordem jurídica pátria, de sorte a não se reputar como legítima nenhuma manifestação legislativa dissonante de seus preceitos fundamentais, os quais servem como verdadeiros vetores interpretativos.

Entretanto, muito embora a doutrina pátria venha afirmando o fato de as sociedades cooperativas não se sujeitarem ao regime falimentar, não dão à matéria o aprofundamento necessário, ou quando o fazem, não abordam os preceitos constitucionais aptos a servir de norte para delimitação escorreita do tema.

Os motivos que levam a não aceitação da submissão das cooperativas ao procedimento de recuperação judicial não são suficientes para afastar o seu escopo primacial que é a preservação atividade econômica, fruto do princípio da função social da propriedade, do qual se extrai a função social da empresa.

Destarte, mostra-se imperiosa a ampliação do alcance da Lei ㄲo. 11.101/2005 às sociedades cooperativas, a fim de não consentir a aplicação da lei a ferro e fogo em claro detrimento do interesse coletivo e das pretensões constitucionais fartamente estruturadas em benefício do cooperativismo e do desenvolvimento social e econômico, objetivos encartados na Constituição da República de 1988.

Pensar diferente seria tomar os meios pelos fins, quando, na verdade, o fim é a preservação das atividades e todo o complexo empreendimento que move a economia local, regional e até mesmo nacional, evitando o impacto nefasto da quebra da cadeia produtiva que pode decorrer da extinção de determinada sociedade, sendo irrelevante para o desiderato constitucional se tratar de sociedade civil ou empresária.

\section{REFERÊNCIAS}

BARROSO, Luis Roberto. Curso de Direito constitucional contemporâneo: os conceitos fundamentais e a construção de um novo modelo. 4. ed. São Paulo: Saraiva, 2013.

BONAVIDES, Paulo. Curso de Direito Constitucional. São Paulo: Malheiros, 2006.

BRASIL, Conselho da Justiça Federal. III Jornada de Direito Civil. Brasília: CJF, 2007.

Constituição (1988). Emenda Constitucional, nº 91, de 19 de fevereiro de 2016. Altera a Constituição Federal para estabelecer a possibilidade, excepcional e em período determinado, de desfiliação partidária, sem prejuízo do mandato. Portal da Legislação, Brasília, fev. 2016. Disponível em: <http://www.planalto. gov.br/ccivil_03/constituicao/constituicaocompilado.htm.> Acesso em: 10 abr. 2018.

. Decreto-Lei no 5.764, DE 16 de dezembro de 1971. Define a Política Nacional de Cooperativismo, institui o regime jurídico das sociedades cooperativas, e dá outras providências. Disponível em: <http://www.planalto.gov.br/ccivil_03/LeIs/L5764.htm>. Acesso em: 10 abr. 2018.

Lei no 10.406, de 10 de janeiro de 2002. Institui o Código Civil. Disponível em: <http://www. planalto.gov.br/ccivil_03/leis/2002/l10406.htm.>. Acesso em: 10 abr. 2018. 
Lei no 11.101 , de 9 de fevereiro de 2005. Regula a recuperação judicial, a extrajudicial e a falência do empresário e da sociedade empresária. Disponível em: <http://www.planalto.gov.br/ ccivil_03/_ato2004-2006/2005/lei/l11101.htm> Acesso em: 10 abr. 2018.

CAMPINHO, Sérgio. Falência e recuperação de empresa: O novo regime da insolvência empresarial. 7. ed. Rio de Janeiro: Renovar, 2015.

CAVALLI, Cássio Machado. O direito da empresa no novo código civil. Revista dos Tribunais, São Paulo. v. 828 , p. $43-78$, out. 2004 .

CHALHUB, Melhin Namen. Função Social da Propriedade. Revista da EMERJ, Rio de Janeiro, v. 6, p. 305-317, 2003.

COELHO, Fábio Ulhoa. Curso de Direito Comercial. 19. ed. São Paulo: Saraiva, 2015.

CORREIA JUNIOR, José Barros. (Re)personalização do Direito Empresarial pela função e atividade social. Revista Fórum de Direito Civil - RFDC, Belo Horizonte, ano 1, n. 1, p. 99-122, set./dez. 2012.

A função social e a responsabilidade social da empresa perante os stakeholders. Tese de dourado apresentada na Universidade Federal de Pernambuco - UFPE. 2013.

DI PIETRO, Maria Sylvia Zenalla. Direito Administrativo. 26. ed. São Paulo: Atlas, 2013.

FAZZIO JÚNIOR, Waldo. Lei de falência e recuperação de empresas. 4. ed. São Paulo: atlas, 2008.

FORNARI, Homero José Nardim. A função social da empresa: elemento decisivo na Recuperação judicial. Revista de Direito Empresarial - RDEmp, Belo Horizonte, ano 12, n. 2, maio/ago. 2015. Disponível em: <http://bdjur.stj.jus.br/jspui/handle/2011/97577 >. Acesso em: 11 nov. 2016.

FRANCO, Vera Helena de Mello. Função social e procedimento recuperacional: a função social sob novo enfoque. Revista Direito \& Justiça, Porto Alegre, v. 41, n. 2, p. 225-237, jul./dez. 2015.

GRAU, Eros Roberto. A ordem econômica na Constituição de 1988. 12. ed. São Paulo: Malheiros, 2007.

Ensaio e discurso sobre a interpretação /aplicação do Direito. São Paulo: Malheiros, 2002.

KOURY, Suzy Cavalcante. Empresa no novo Código Civil: conceituação e dicotomia entre sociedades simples e empresárias. Revista de Direito Privado, São Paulo, v. 22, p. 277 - 287. abr./jun. 2005.

MAMEDE, Gladston. Direito Empresarial Brasileiro: falência e recuperação de empresas. 5. ed. São Paulo: Atlas, 2012.

MAXIMILIANO, Carlos. Hermenêutica e Aplicação do Direito. 13. ed. Rio de Janeiro: Forense, 1993.

PACHECO, José da Silva. Análise jurídica de conceitos básicos de direito empresarial. Doutrinas Essenciais de Direito Empresarial. vol. 1, p. 157. dez, 2010.

RAMOS, André Santa Cruz. Direito Empresarial Esquematizado. 2. ed. Rio de Janeiro: Forense, 2012. 
REQUIÃO, Rubens. Curso de Direito Comercial. 27. ed. rev. e atual. São Paulo: Saraiva, 2008. Volume 1. ROCHA, Silvio Luiz Ferreira da. Função Social da Propriedade Pública. São Paulo: Malheiros, 2005.

SILVA, Juliana Giovanetti Pereira da. A publicização do Direito Comercial e a função social da empresa. Revista de Direito Empresarial, Belo Horizonte, ano 12, n. 1, p. 215-229, jan./abr. 2015.

SCALZILLI, Fabrício Nedel. Cooperativa Agrícola e Recuperação Judicial. Valor Econômico. Abril/2014. Disponível em: <http://www.valor.com.br/legislacao/3686064/cooperativa-agricola-e-recuperacaojudicial> Acesso em: 19 mar. 2017.

SZTAJN, Rachel. Notas sobre o conceito de empresário e empresa no Código Civil Brasileiro. Revista de Direito Privado. São Paulo, v. 25, p. 233 - 249. Jan/mar. 2006.

STRECK, Lênio. Hermenêutica jurídica e(m) crise. 4. ed. Porto Alegre: Livraria do Advogado, 2003.

TOKARS, Fábio Leandro. Recuperação judicial de cooperativas. Martins Bertoldi. 2009. Disponível em: <http://www.marinsbertoldi.com.br/artigos/recuperacao-judicial-de-cooperativas/> Acesso em: 20 jan. 2017. 